\title{
Congenital heart disease and cardiac surgery in childhood: effects on cognitive function and academic ability
}

\author{
J Wray, T Sensky
}

\begin{abstract}
Objective-To evaluate changes in cognitive and academic functioning following cardiac surgery in children with congenital heart disease.

Design-A prospective cross sectional study in which patients were assessed immediately before treatment and 12 months later.

Patients-Three groups of children aged 3.5-17 years: a group with congenital heart disease awaiting surgery, another awaiting bone marrow transplantation, and a healthy comparison group.

Main outcome measures-Intelligence quotient and measures of academic attainment, evaluated with the British Ability Scales.

Results-Preoperatively, children with cyanotic lesions showed deficits in comparison with those with acyanotic lesions. Postoperatively, children with cyanotic lesions showed a deterioration in performance and achieved significantly lower scores than those with acyanotic lesions. While there were significant differences between the congenital heart disease and bone marrow transplantation groups preoperatively, these were no longer apparent at follow up.

Conclusions-In contrast to previously published findings, the present results suggest that cardiac surgery does not result in early postoperative improvements in cognitive function for children with congenital heart disease. The nature of the cardiac lesion continues to affect cognitive and academic performance, even after surgery.

(Heart 2001;85:687-691)
\end{abstract}

Keywords: congenital heart disease; cardiac surgery; cognitive ability

Surveys of children with congenital heart disease have shown that their intellectual abilities are within the normal range, albeit at the lower end. ${ }^{12}$ Nevertheless it is widely accepted that the presence of a congenital heart defect can have deleterious effects on intelligence. Cognitive impairment has been reported in older children with congenital heart disease, particularly those with cyanotic lesions. ${ }^{3-6}$ Such impairment has been attributed to the effects of chronic hypoxia, ${ }^{7}$ but it is questionable whether this alone is responsible. Additional postulated risk factors include physical incapacity because of the cardiac lesion and parental overprotection. ${ }^{8}$

Research to date has yielded conflicting results. Although surgical intervention has been reported to lead to a significant increase in intelligence quotient (IQ) scores, ${ }^{9}$ particularly in children with cyanotic lesions, ${ }^{5}{ }^{10}$ such children may continue to show significant cognitive and neurodevelopmental impairment. ${ }^{11-13}$

For children with cyanotic lesions, age at the time of surgical repair may be important, but research evidence is again contradictory. An association has been reported between postponing repair and progressive impairment of cognitive function. ${ }^{14-16}$ However, a more recent study found no relation between intellectual function 10 years after surgery and age of repair in cyanotic congenital heart disease. ${ }^{17}$

Most studies to date have focused on IQ. Academic functioning in the child with congenital heart disease has received little attention, despite increasing recognition of the impact of chronic illness on school performance. A recent study reported that children with surgically corrected cyanotic lesions had significantly poorer performance in all areas of academic functioning compared with a group of children with previously diagnosed innocent murmurs or a spontaneously closing ventricular septal defect. ${ }^{18}$ Poor concentration ${ }^{19}$ and learning difficulties ${ }^{20} 21$ have also been reported.

The contradictory findings of research to date are attributable at least in part to methodological limitations of the published studies. In particular, most studies have been retrospective or cross sectional, and few have included appropriate control groups. In the present study we aimed to overcome these limitations by using a prospective design and including two comparison groups, one of children undergoing bone marrow transplantation and another of healthy children. In this paper we focus on children older than 3.5 years of age. The situation for younger children is likely to be somewhat different. ${ }^{22}$

We aimed to test the following hypotheses, based on the existing reports as reviewed above:

- Children with congenital heart disease will show cognitive and developmental impairment relative to healthy children and to children awaiting bone marrow transplantation.

- Preoperatively, children with cyanotic lesions will show a greater degree of cognitive impairment than those with acyanotic lesions. 
- Corrective surgery will result in a greater improvement in cognitive functioning in children with cyanotic lesions than in those with acyanotic lesions.

- For children with cyanotic defects, postoperative cognitive impairment will be positively correlated with age at time of repair, but no such association will be found for children with acyanotic lesions.

\section{Methods}

SAMPLE

The children in the study were aged $3.5-17$ years. The congenital heart disease sample comprised a consecutive series of children admitted for elective surgery recruited from three specialist units in London over a period of two years. Forty four of the children (94\%) underwent corrective surgery, with three having palliative shunts, and in 40 cases ( $85 \%$ ) the interventions were open heart procedures. The bone marrow transplant sample was made up of a consecutive series of children recruited over 33 months from four specialist units. The healthy group was recruited from a dental clinic and from two schools in London.

Characteristics of the sample are summarised in table 1 . The congenital heart disease group comprised 47 children, 17 with cyanotic lesions and 30 with acyanotic lesions (the "cyanotic" and "acyanotic" groups, respectively). The mean (SD) ages of the two congenital heart disease subgroups were not significantly different (cyanotic group, 7.5 (3.5) years; acyanotic group, 7.3 (3.0) years). The bone marrow transplantation and healthy groups each comprised 51 children. The groups did not differ in their mean ages, sex distributions, or parents' socioeconomic status (table 1).

PROCEDURE

Children in the congenital heart disease and bone marrow transplant groups were assessed before surgery or transplantation, respectively, and again 12 months after these procedures. The healthy group was assessed on two occasions, 12 months apart.

MEASURES

Intellectual ability

This was assessed using a short form IQ estimate of the British Ability Scales (BAS), ${ }^{23}$

Table 1 Characteristics of the initial sample

\begin{tabular}{llll}
\hline & CHD & BMT & Healthy \\
\hline Sample & & & \\
$\quad$ Children recruited & 47 & 51 & 51 \\
$\quad$ Initial assessments & 47 & 47 & 51 \\
$\quad$ Follow up assessments & 35 & 28 & 35 \\
$\quad$ Lost to follow up & 7 & 3 & 16 \\
$\quad$ Died & 5 & 20 & 0 \\
Age (years) & & & \\
$\quad$ Range & $3.5-14.8$ & $3.6-16.7$ & $3.8-16.8$ \\
$\quad$ Mean & 7.4 & 8.7 & 8.8 \\
$\quad$ SD & 3.2 & 3.4 & 3.4 \\
Sex & & & \\
$\quad$ Male & $20(43 \%)$ & $25(49 \%)$ & $25(49 \%)$ \\
$\quad$ Female & $27(57 \%)$ & $26(51 \%)$ & $26(51 \%)$ \\
Socioeconomic status & & & \\
$\quad$ Non-manual & $25(53 \%)$ & $25(49 \%)$ & $27(53 \%)$ \\
$\quad$ Manual & $22(47 \%)$ & $26(51 \%)$ & $24(47 \%)$ \\
\hline
\end{tabular}

BMT, bone marrow transplantation; CHD, congenital heart disease. comprising measures of verbal and non-verbal reasoning ability, short term memory, speed of information processing, and retrieval of knowledge skills. The scales have been validated in a British population and have been used in a wide range of diagnostic contexts as an aid in identification, classification, and selection of children with learning difficulties. ${ }^{23}{ }^{24}$ They have also been used in the study of children with chronic illness. ${ }^{25}{ }^{26}$ The BAS were chosen in preference to the Wechsler scales ${ }^{27}$ because of their standardisation on a British rather than an American population, and also because they are intended for use across a wide age range. An adequate correlation has been reported between the BAS and Wechsler scales. ${ }^{23}{ }^{25}$

\section{Academic performance}

Children aged 3.5-14.5 years completed the BAS basic number skills attainment test to assess arithmetic, and children aged 5-14.5 years completed the BAS word reading subtest and the Schonell graded spelling test. ${ }^{28}$ These measures of academic attainment have been used previously in studies of chronically ill children. $^{29}$

\section{Parental interviews}

On both test occasions, parents took part in a semistructured interview which included questions about the child's behaviour and attendance at school.

STATISTICAL ANALYSIS

To assess each child's overall academic attainment, a score of their achievement on the arithmetic and reading tests was calculated relative to overall IQ. ${ }^{23}{ }^{30} \mathrm{An}$ achievement score of more than 1 SD below the overall IQ score was used as the criterion for underachievement. The prevalence of reading problems was also investigated using as a criterion a score of more than $1 \mathrm{SD}$ below the norm on the reading scale.

Cognitive measures at each test occasion were compared across the groups by analysis of variance, using Scheffés multiple comparison tests (setting $\mathrm{p}<0.05$ ) for post hoc comparisons. Independent $t$ tests were used for comparisons between the cyanotic and acyanotic groups. Changes over time were assessed within groups using paired $t$ tests and between groups using repeated measures analysis of variance. Correlations of age and performance were measured using Pearson correlation coefficients. The differences between the groups in the prevalence of underachievement on academic variables and reading problems were assessed using $\chi^{2}$ tests.

\section{Results}

INITIAL ASSESSMENTS

Overall, the percentages of cardiac children scoring within the normal range for IQ and school attainments ranged from $69 \%$ for spelling to $89 \%$ on overall IQ, with all three groups (congenital heart disease, bone marrow transplantation, and healthy) showing mean scores within the normal range on each measure. Overall IQ was also not significantly different 
Table 2 Initial scores by group

\begin{tabular}{|c|c|c|c|c|c|}
\hline \multirow[b]{3}{*}{ Test } & \multicolumn{5}{|l|}{ Group } \\
\hline & \multicolumn{3}{|l|}{$C H D$} & \multirow[b]{2}{*}{$B M T$} & \multirow[b]{2}{*}{ Healthy } \\
\hline & Cyanotic & Acyanotic & Total & & \\
\hline Recall of digits & $49(2)$ & $53(2)$ & $52(1)$ & $49(1)^{i}$ & $53(1)^{j}$ \\
\hline Visual recognition & $52(5)$ & $63(6)$ & $58(4)$ & $63(5)$ & $58(4)$ \\
\hline Naming vocabulary & $51(3)$ & $57(2)$ & $55(2)$ & $50(2)$ & $54(2)$ \\
\hline Verbal reasoning & $49(4)$ & $54(1)$ & $52(2)$ & $55(3)$ & $56(2)$ \\
\hline Matrices & $47(4)^{\mathrm{a}}$ & $62(2)^{\mathrm{a}}$ & $57(2)$ & $53(1)$ & $56(1)$ \\
\hline Similarities & $48(4)$ & $55(2)$ & $53(2)$ & $51(1)$ & $54(1)$ \\
\hline Information processing speed & $41(4)^{\mathrm{b}}$ & $60(4)^{\mathrm{b}}$ & $52(4)^{i}$ & $56(2)$ & $61(2)^{i}$ \\
\hline Overall IQ & $96(5)^{\mathrm{c}}$ & $115(3)^{\mathrm{c}}$ & $108(3)$ & $105(2)^{k}$ & $111(2)^{\mathrm{k}}$ \\
\hline Arithmetic & $98(5)^{d}$ & $112(3)^{d}$ & $107(3)^{\mathrm{g}}$ & $98(2)^{\mathrm{gl}}$ & $105(2)^{1}$ \\
\hline Reading & $93(5)^{\mathrm{e}}$ & $107(4)^{\mathrm{e}}$ & $103(3)^{\mathrm{h}}$ & $93(3)^{\mathrm{hm}}$ & $105(2)^{\mathrm{m}}$ \\
\hline Spelling & $81(6)^{\mathrm{f}}$ & $98(3)^{\mathrm{f}}$ & $93(3)$ & $87(3)^{\mathrm{n}}$ & $98(2)^{\mathrm{n}}$ \\
\hline
\end{tabular}

Values are mean (SEM).

95\% Confidence interval of differences between means for data with the same superscript letter: $\mathrm{a}:-24.1$ to $-5.5, \mathrm{p}<0.01 ; \mathrm{b}:-31.6$ to $-6.4, \mathrm{p}<0.01$; $:-30.1$ to $-7.6, \mathrm{p}<0.01$; $\mathrm{d}:-26.0$ to -0.8 , $\mathrm{p}<0.05$; e: -27.8 to -1.2 , p < 0.05 ; f: -31.3 to $-3.6, \mathrm{p}<0.01$; g: 1.9 to 16.5 , p < 0.05; h: 1.6 to $18.2, \mathrm{p}<0.05$; i: -16.7 to $-1.8, \mathrm{p}<0.05$; $\mathrm{j}:-7.91$ to -0.23 , p < 0.05 ; $\mathrm{k}:-11.78$ to -1.07 , $\mathrm{p}<$ 0.05 ; $1:-13.96$ to $-1.25, \mathrm{p}<0.05$; $\mathrm{m}:-19.45$ to $-6.06, \mathrm{p}<0.001 ; \mathrm{n}:-18.29$ to $-3.16, \mathrm{p}<0.01$. IQ, intelligence quotient.

Table 3 Academic underachievement: number of children underachieving (percentages in parentheses)

\begin{tabular}{|c|c|c|c|c|c|}
\hline & \multicolumn{5}{|l|}{ Group } \\
\hline & \multicolumn{3}{|l|}{$C H D$} & \multirow[b]{2}{*}{$B M T$} & \multirow[b]{2}{*}{ Healthy } \\
\hline & Cyanotic & Acyanotic & Total & & \\
\hline \multicolumn{6}{|l|}{ Initial assessment } \\
\hline Arithmetic underachievement & $1(8)$ & $3(13)$ & $4(11)$ & $9(22)$ & $11(28)$ \\
\hline Reading underachievement & $2(17)$ & $7(29)$ & $9(25)$ & $13(37)^{\mathrm{a}}$ & $7(18)^{\mathrm{a}}$ \\
\hline Reading problems & $4(33)$ & $2(8)$ & $6(17)$ & $12(34)$ & $3(8)$ \\
\hline \multicolumn{6}{|l|}{ Follow up assessment } \\
\hline Arithmetic underachievement & $1(10)$ & $7(33)$ & $8(26)$ & $8(35)$ & $8(27)$ \\
\hline Reading underachievement & $2(25)$ & $5(25)$ & $7(25)$ & $9(39)^{\mathrm{b}}$ & $3(10)^{b}$ \\
\hline Reading problems & $4(50)^{\mathrm{c}, \mathrm{d}}$ & $1(5)^{\mathrm{c}, \mathrm{e}}$ & $5(18)$ & $9(39)^{\mathrm{e}, \mathrm{f}}$ & $3(10)^{d, f}$ \\
\hline
\end{tabular}

95\% Confidence interval of differences between means for data with the same superscript letter: a: -0.0080 to $0.392, p=0.01 ; b:-0.0648$ to $0.518, p=0.03 ; \mathrm{c}: 0.0906$ to $0.809, p=0.02$; : 0.0373 to $0.763, \mathrm{p}=0.04$; e: -0.5620 to $-0.120, \mathrm{p}=0.02 ; \mathrm{f}: 0.0648$ to $0.518, \mathrm{p}=0.03$.

Table 4 Follow up scores by group

\begin{tabular}{|c|c|c|c|c|c|}
\hline \multirow[b]{3}{*}{ Test } & \multicolumn{5}{|l|}{ Group } \\
\hline & \multicolumn{3}{|l|}{$C H D$} & \multirow[b]{2}{*}{$B M T$} & \multirow[b]{2}{*}{ Healthy } \\
\hline & Cyanotic & Acyanotic & Total & & \\
\hline Recall of digits & $51(4)^{a}$ & $59(2)^{a}$ & $56(2)$ & $52(2)$ & $55(2)$ \\
\hline Visual recognition & $56(9)$ & $66(-)$ & $58(7)$ & $66(-)$ & $52(-)$ \\
\hline Naming vocabulary & $47(4)^{\mathrm{b}}$ & $58(2)^{b}$ & $54(2)$ & $52(5)$ & $52(2)$ \\
\hline Verbal reasoning & $45(8)$ & $60(-)$ & $49(6)$ & $58(-)$ & $58(-)$ \\
\hline Matrices & $48(5)$ & $56(2)$ & $54(2)$ & $53(2)$ & $56(2)$ \\
\hline Similarities & $46(4)^{c}$ & $57(2)^{c}$ & $55(2)$ & $53(2)$ & $54(1)$ \\
\hline Information processing speed & $34(4)^{\mathrm{d}}$ & $61(2)^{d}$ & $55(4)$ & $52(2)^{\mathrm{h}}$ & $60(2)^{\mathrm{h}}$ \\
\hline Overall IQ & $96(7)^{\mathrm{e}}$ & $116(2)^{\mathrm{e}}$ & $110(3)$ & $106(3)$ & $111(2)$ \\
\hline Arithmetic & $98(6)$ & $109(3)$ & $106(3)$ & $97(3)$ & $103(3)$ \\
\hline Reading & $86(6)^{\mathrm{f}}$ & $109(4)^{\mathrm{f}}$ & $102(4)$ & $93(4)^{\mathrm{i}}$ & $107(3)^{\mathrm{i}}$ \\
\hline Spelling & $78(6)^{\mathrm{g}}$ & $101(4)^{\mathrm{g}}$ & $94(4)$ & $87(4)^{i}$ & $100(3)^{j}$ \\
\hline
\end{tabular}

Values are mean (SEM).

$95 \%$ Confidence interval of differences between means for data with the same superscript letter: a: -14.9 to $-0.2, \mathrm{p}<0.05$; $\mathrm{b}:-19.3$ to $-1.6, \mathrm{p}<0.05$; $\mathrm{c}:-18.3$ to $-3.2, \mathrm{p}<0.01$; $\mathrm{d}:-37.8$ to -15.5 , p < 0.01 ; e: -31.9 to -8.8 , p < 0.01; f: -37.9 to $-9.6, \mathrm{p}<0.01$; $\mathrm{g}:-37.3$ to $-7.8, \mathrm{p}<0.01$; h: -14.34 to $-1.33, \mathrm{p}<0.05$; i: -22.60 to -4.52 , $\mathrm{p}<0.01$; $\mathrm{j}:-23.13$ to $-4.43, \mathrm{p}<0.01$.

between the cardiac and reference groups (table 2). However, the congenital heart disease group performed poorly on information processing compared with the healthy group (table 2). The bone marrow transplantation group showed significantly lower scores on arithmetic and reading ability than the congenital heart disease group (table 2), which was also reflected in a higher frequency of underachievement in reading (table 3 ).

Compared with the acyanotic subgroup, the children with cyanotic lesions had lower overall
IQ scores (with, in particular, significantly poorer performance on the matrices and information processing speed subscales). They also showed lower ability levels for arithmetic, reading, and spelling (table 2) as well as higher rates of underachievement in reading (table 3 ).

FOLLOW UP ASSESSMENTS

The percentages of cardiac children scoring within the normal range for IQ and school attainments at follow up were similar to those of the baseline assessment, ranging from $71 \%$ for spelling to $89 \%$ on overall IQ, with all three groups showing mean scores within the normal range for each measure. However, the differences noted above between the cardiac and reference groups at initial assessment were no longer apparent at follow up. The frequency of reading problems remained higher in the bone marrow transplant group than in the healthy group (table 3 ), and the bone marrow transplant and healthy groups still differed significantly on reading and spelling (table 4).

The cyanotic subgroup continued to show impaired performance relative to both the healthy group and the acyanotic subgroup. Compared with the healthy group, the cyanotic subgroup had lower overall IQ scores, performed less well on the speed of information processing subtest, and showed poorer performance on reading and spelling (table 4). Accordingly there were more underachievers in reading in the cyanotic subgroup than in the healthy group. Compared with the acyanotic group, the cyanotic group had significantly lower IQ scores and poorer performance in reading and spelling (table 4 ), and a greater frequency of reading problems (table 3 ).

CHANGES OVER TIME

The healthy group showed no significant changes between the initial and follow up assessments. For the cardiac group as a whole, although overall IQ did not change postoperatively, there were significant deteriorations in two subtests-matrices ( $95 \%$ confidence interval (CI) for difference between initial and follow up assessments 3.29 to 9.23, p < 0.001) and arithmetic $(95 \%$ CI for difference between initial and follow up assessment 0.11 to 10.79 , $\mathrm{p}=0.046)$.

Although the cyanotic subgroup fared worse at follow up than initially on every subtest, none of these differences was significant. Changes in the acyanotic group were less consistent: although digit recall improved at follow up $(95 \%$ CI of difference -7.6 to -0.3 , $\mathrm{p}<0.01)$, performance on matrices deteriorated $(95 \%$ CI of difference 4.0 to 9.8 , $\mathrm{p}<0.01)$.

EFFECTS OF AGE

At follow up there was a significant negative correlation between arithmetical ability and age at repair in both congenital heart disease subgroups (cyanotic group: $r=-0.6890$, $\mathrm{p}=0.014 ;$ acyanotic group: $r=-0.4867$, $\mathrm{p}=0.013)$. The effect of age on the difference in performance between the two subgroups 
was significant on the arithmetic test $(t=-3.585, \mathrm{p}=0.001)$.

CHILDREN NOT FOLLOWED UP

In general, the preoperative performance of those children who were lost to follow up resembled that of the follow up sample except that they showed lower scores on naming vocabulary $(\mathrm{p}=0.015)$ and digit recall $(p=0.032)$. By contrast, the children who died performed at significantly lower levels than the follow up sample on the majority of indices, including matrices $(\mathrm{p}<0.0005)$, similarities $(\mathrm{p}=0.004)$, and recall of digits $(\mathrm{p}=0.010)$, as well as on overall IQ $(\mathrm{p}<0.0005)$, arithmetic $(\mathrm{p}=0.004)$, and spelling $(\mathrm{p}=0.022)$.

\section{PARENTAL INTERVIEWS}

Preoperatively, dependency and inactivity were the two main areas of concern mentioned by parents, particularly those of children with cyanotic lesions. Postoperatively, increases in activity levels and in disobedient behaviour were reported. Anecdotally, parents of some children with cyanotic lesions reported that their own anxiety levels resulted in overprotection of the patient and consequent limitations of independent behaviour.

The children returned to school on average three months after surgery (range 1-12 months). The cyanotic group took an average of 3.5 months to return to school compared with a mean time of 2.5 months for the acyanotic group, but this difference was not significant.

\section{Discussion}

Our study aimed to overcome methodological limitations in most earlier studies by using a prospective design and by comparing children with congenital heart disease with samples of healthy children and children awaiting bone marrow transplantation, in an attempt to distinguish between effects of congenital heart disease and those attributable to chronic physical illness. The children recruited into the congenital heart disease and bone marrow transplant groups should be representative of those treated in specialist centres, except that children with significant learning impairments were excluded. Some children were lost to follow up. Those lost through perioperative death showed poorer intellectual functioning at initial assessment. However, those who could not be followed up for other reasons closely resembled the children who were successfully followed up, reinforcing the representativeness of the final sample. Despite this careful attention to methodology, the study has two important limitations that must be borne in mind when interpreting the results. Firstly, the sample size was small, increasing the risks of type II statistical errors. Secondly, in the congenital heart disease group no account was taken of the severity of the initial cardiac problems or of the extent to which they were successfully treated by surgery. Separation of the congenital heart disease sample into cyanotic and acyanotic subgroups, although widely used in research, is a relatively crude measure, but, given the small sample size, it would have been difficult to introduce a further variable into the analyses.

The results provide only partial support for the study hypotheses. Preoperatively, although the bone marrow transplant group showed evidence of lower academic attainment than the healthy group, the cardiac group as a whole showed only minimal differences from the healthy group either in intellectual functioning or in academic attainment. Children with acyanotic lesions and healthy children achieved higher scores than would be expected from the standardised norms for the tests. ${ }^{23}{ }^{24}$ This has been reported previously ${ }^{31-33}$ and most probably reflects the fact that the standardised norms are no longer accurate.

Contrary to earlier work, ${ }^{5}$ the acyanotic subgroup did not differ from the healthy group. Parents are now given more encouragement to treat their children normally than they might have been in the 1960s. Also, schools are now more accustomed to dealing with children with congenital heart disease. Both these factors should encourage normal development.

The cyanotic and bone marrow transplant groups were broadly comparable in their results, both differing from the healthy group. The differences between these groups and the acyanotic group suggest that-for older children at least - the nature of the disease is a significant factor in cognitive development rather than chronic illness per se. Their poorer performance on the academic indices supports the view that schooling is affected, despite IQ being within the normal range.

Preoperative differences between the cyanotic and acyanotic subgroups are consistent with previous published reports. ${ }^{6}{ }^{7}$ Among the cyanotic children, academic performance was in line with overall IQ. Although the acyanotic children had a higher overall IQ, more of them were performing below their potential, as reported in studies of children with other chronic illnesses. ${ }^{34-39}$ The differences observed in the present study between the cyanotic and acyanotic subgroups were not found among younger (preschool) children, ${ }^{22}$ supporting the view that in children with cyanotic lesions, impairment of cognitive function increases with age. ${ }^{1415}$ These results also suggest that there may be a critical age for correction of cyanotic lesions, after which cyanosis and its consequences have deleterious effects on development and cognition. As well as direct effects of hypoxia and other heart related factors, it is also likely that more prolonged cyanosis influences parenting attitudes, treatment of the child by teachers and peers, and self esteem, all of which could affect cognitive and academic performance. However, our results-in common with those of another recent $\operatorname{study}^{17}$ failed to support the reported relationship between age at time of repair and subsequent cognitive function in patients with cyanotic lesions. $^{14-16}$ These studies involved a single diagnosis (transposition of the great arteries) and it may be that this effect is specific to this diagnosis. Our cyanotic subgroup was small in size and also diagnostically heterogeneous. 
For the acyanotic subgroup, the minimal changes in intellectual and academic performance following surgery are hardly surprising, given the absence of any differences preoperatively between these children and the healthy group. In the cyanotic subgroup, the failure to find significant improvement in cognitive function postoperatively supports other published data $^{18}$ and is in contrast with an earlier report of improved cognitive function after surgery. ${ }^{5}$ Possible reasons for the failure to find improvements after surgery in the cyanotic group include the following:

- the possibility that our patients had more complex disease than reported previously;

- the fact that four children in this group required readmission to hospital, thus interfering with academic progress;

- three of these children continued to be symptomatic, because they had had palliative rather than corrective surgery;

- children in the cyanotic group missed more school during follow up than those in the acyanotic group, even though the interval between surgery and return to school was no different in the two groups.

The findings for the bone marrow transplantation and cyanotic groups were very similar and contrasted with the results for the acyanotic subgroup. The lack of change at follow up of the bone marrow transplant group again suggests that cognitive functioning is influenced more by the underlying disorder than by its treatment, and that there are effects on academic performance which persist beyond successful treatments of the main physical problems. $^{35} 363839$

The present results suggest that for older children at least the nature of the underlying disease influences cognitive and academic functioning more than the success of treatment. Children with acyanotic lesions have a good prognosis for future cognitive performance. As with preschool children, ${ }^{22}$ this prospective controlled study of young children of school age has highlighted the particular vulnerability of children with cyanotic lesions. Cognitive and academic performance deficits may decline as time after surgery increases, ${ }^{17}$ and longer term follow up is now required to determine the extent to which the observed impairments in children with cyanotic lesions endure, and what particular factors contribute to their longer term outcome.

This work was funded by the Garfield Weston Trust, the Cancer Research Campaign, the Westminster Hospital Trustees, and the Lord Ashdown Charitable Settlement. The cooperation of Professor H Zeitlin and Dr C Pot-Mees, formerly of Westminster Children's Hospital, during the stage of data collection is ster Children's Hospital,
gratefully acknowledged.

1 Chazan M, Harris T, O’Neill D, et al. The intellectual and emotional development of children with congenital heart disease. Guys Hospital Report 1951:331-41.

2 Kramer HH, Awiszus D, Sterzel U, et al. Development of personality and intelligence in children with congenital heart disease. $\mathcal{F}$ Child Psychol Psychiatry 1989;30:299-308.

3 Feldt RH, Ewert JC, Stickler GB, et al. Children with congenital heart disease: motor development and intelligence. Am 7 Dis Child 1969;117:281-7.

4 Silbert A, Wolff PH, Mayer B, et al. Cyanotic heart disease and psychological development. Pediatrics 1969;43:192-200. 5 Linde LM, Rasof B, Dunn OJ. Longitudinal studies of intellectual and behavioral development in children with lectual and behavioral development in children with 76 .
6 DeMaso DR, Beardslee WR, Silbert AR, et al. Psychological functioning in children with cyanotic heart defects. $7 \mathrm{Dev}$ Behav Pediatr 1990;11:289-94.

7 O'Dougherty M, Wright FS, Loewenson RB, et al. Cerebral dysfunction after chronic hypoxia in children. Neurology 1985;35:42-6.

8 Linde LM, Rasof B, Dunn OJ. Mental development in congenital heart disease. F Pediatr 1967;71:198-203.

9 Meyendorf R, Jansch G, Trondle C, et al. Psychiatric complications in children after heart surgery: a pre- and postoperative comparison of 4- to 13 -year-olds. Z Kinder postoperative comparison of 4-

10 Sunderland CO, Matarazzo RG, Lees MH, et al. Total correction of tetralogy of Fallot in infancy. Postoperative hemodynamic evaluation. Circulation 1973;48:398-405.

11 Hesz N, Clark EB. Cognitive development in transposition of the great vessels. Arch Dis Child 1988;63:198-200.

12 Mendoza JC, Wilkerson SA, Reese AH. Follow-up of patients who underwent arterial switch repair for transposition of the great arteries. Am ₹ Dis Child 1991;145:40-3.

13 Shampaine EL, Nadelman L, Rosenthal A, et al. Longitudinal psychological assessment in tetralogy of Fallot. Pediatr Cardiol 1990;10:135-40.

14 O'Dougherty M, Wright FS, Garmezy N, et al. Later competence and adaptation in infants who survive severe heart defects. Child Dev 1983;54:1129-42.

15 Newburger JW, Silbert AR, Buckley LP, et al. Cognitive function and age at repair of transposition of the great arteries in children. $N$ Engl F Med 1984;310:1495-9.

16 Newburger JW, Tucker AD, Silbert AR, et al. Motor function and timing of surgery in transposition of the great arteries, intact ventricular septum [abstract]. Pediatr Cardiol 1983;4:317.

17 Oates RK, Simpson JM, Cartmill TB, et al. Intellectual function and age of repair in cyanotic congenital heart disease. Arch Dis Child 1995;72:298-301.

18 Wright $M$, Nolan T. Impact of cyanotic heart disease on chool performance. Arch Dis Child 1994;71:64-70.

19 Kallfelz HC, Kaemmerer H, Luhmer I, et al. Psychointellectual performance after correction of complex congenital heart defects. In: Walter PJ, ed. Quality of life after open heart surgery. The Netherlands: Kluwer Academic Publishers, 1992:315-21.

20 Dhont M, De Wit E, Verhaaren H, et al. Quality of life after surgical correction of congenital heart disease: the parents' point of view. In: Walter PJ, ed. Quality of life after open heart surgery. The Netherlands: Kluwer Academic Publishers, 1992:347-53.

21 Turina M, Pasic M, Fry M, et al. Long-term results after atrial correction of transposition of the great vessels. In: Walter PJ, ed. Quality of life after open heart surgery. The Netherlands: Kluwer Academic Publishers, 1992:267-75.

22 Wray J, Sensky T. Controlled study of preschool development after surgery for congenital heart disease. Arch Dis Child 1999;80:511-16.

23 Elliott CD. The British Ability Scales: introductory handbook, technical handbook and manuals for administration and scoring. Windsor: NFER-Nelson, 1983.

24 Elliott CD. The factorial structure and specificity of the British ability scales. Br F Psychol 1986;77:175-85.

25 Jannoun L. Are cognitive and educational development affected by age at which prophylactic therapy is given in acute lymphoblastic leukaemia? Arch Dis Child 1983;58: 953-8.

26 Twaddle V, Britton PG, Craft AC, et al. Intellectual function after treatment for leukaemia or solid tumours. Arch Dis Child 1983;58:949-52.

27 Wechsler D. Wechsler intelligence scale for children-revised. New York: Psychological Corporation, 1974.

28 Schonell FJ; Schonell FE. Diagnostic and attainment testing. Edinburgh: Oliver and Boyd, 1949.

29 Jannoun L, Chessells JM. Long-term psychological effects of childhood leukemia and its treatment. Pediatr Hematol Oncol 1987;4:293-308.

30 Thomson ME. The assessment of children with specific reading difficulties (dyslexia) using the British Ability Scales. Br f Psychol 1982;73:461-78.

31 Fulton M, Raab G, Thomson G, et al. Influence of blood lead on the ability and attainment of children in Edinburgh. Lancet 1987; i:1221-6.

32 Cockburn J, Ounsted M. The British ability scales: some differences between scores for Oxfordshire children and the standardisation sample. Bull Br Psychol Soc 1983;36:83-4.

33 Fuggle PW, Tokar S, Grant DB, et al. Rising IQ scores in British children: recent evidence. F Child Psychol Psychiatry 1992;33:1241-7.

34 Olch D. Effects of hemophilia upon intellectual growth and academic achievement. $\mathcal{F}$ Genet Psychol 1971;119:63-74.

35 Pless IB, Pinkerton P. Chronic childhood disorder: promoting patterns of adjustment. London: Henry Kimpton, 1975.

36 Eiser C. Effects of chronic illness on intellectual development. Arch Dis Child 1980;55:766-70.

37 Gath A, Smith MA, Baum JD. Emotional, behavioural, and educational disorders in diabetic children. Arch Dis Child 1980;55:371-5.

38 Mearig JS. Cognitive development of chronically ill children. In: Hobbs N, Perrin JM, eds. Issues in the care of children with chronic illness. San Francisco: Jossey-Bass, 1985:672-97.

39 Peckham VC, Meadows AT, Bartel N, et al. Educational late effects in long-term survivors of childhood acute lymphocytic leukemia. Pediatrics 1988;81:127-33. 